\title{
Improving Distribution System Performance in Deregulated Electricity Industry Using Phase-Constrained Billing Scheme
}

\author{
Damian O. Dike, George E. Ogu, N. Chukwuchekwa and Blessing C. Dike \\ (Electrical and Electronic Engineering Department, School of Engineering and Engineering Technology, \\ Federal University of Technology, Owerri (FUTO), Nigeria)
}

\begin{abstract}
In many developing countries, domestic electricity consumers having single phase appliances are most times supplied with single phase meters with incoming three phase supply lines. Due to frequent phase faults, these customers often change their supply from one phase to another whenever there is low voltage or no supply in the phase they are currently connected to. This action coupled with the fact that there is uneven distribution of loads on the distribution transformers in residential areas, lead to more transformer overload with consequential loss of power, equipment, man-hours, revenue and in extreme cases, life. When electricity was treated as a welfare commodity or as part of government social responsibility, these consequences where ignored. But with commercialization, privatization and deregulation, cost minimization and profit maximization have become the watchwords. As a means of minimizing this, utilizing the concept of phase-constrained electricity billing scheme in the deregulated Nigerian Power Industry was presented in this work. The phaseconstrained billing model involves re-arranging the service lines and setting up constraint matrices to relate the phase and service lines utilizable by customer to the electricity bill using penalty factors. To test the acceptability of this model, a customer behavior and utilization index based questionnaires were administered in the field. The survey was analyzed using the statistical attitude measurement technique based on the 5-point Likert Scale. The responses obtained showed that introducing a penalty factor in the billing which ensure that those using more phases pay higher will minimize frequent change of phases; and provide a direction for utilities and customers in resolving the power quality and availability problems associated with frequent phase changing.
\end{abstract}

Keywords: Cost minimization, Deregulation, Penalty factor, Phase constrained, Profit maximization

\section{Introduction}

Residential electricity consumers use single phase appliances which require single phase meters with only incoming single phase (i.e. one phase and neutral lines). In developed countries there is regular supply of stable electricity with balanced load distribution. In purely residential estate, just a pair of cables can supply a whole street from an 11:0.415kV neighborhood transformer and electricity retail companies are available at short notices attending to the consumers. In this wise, the end-users have no need to touch their electricity supply terminals, thereby saving cost.

Unfortunately this is not the case in Nigeria and most other developing countries. Due to frequent outages and irregular supply of electricity in these countries arising from multifarious reasons including phase faults, customers often change their supplies from one phase to another whenever there is low voltage or no supply in the phase they are currently connected to. This action coupled with the fact that there is uneven distribution of loads on the distribution transformers in residential areas, lead to more transformer overload with consequential loss of power, with its commensurate dire consequences. When electricity was treated as a welfare commodity or as part of government social responsibility, these aftermaths where ignored. But with recent changes in ownership and management of power utilities in these countries from regulated and vertically integrated systems to deregulated, unbundled, commercialization and privatized entities, profit maximization has become the watchword.

In a bid to survive the stiff competition, firms who have paid dearly to purchase these utilities from government with much technical know-how, have to introduce electricity billing systems (Meters) with every factor that adds to cost of operation included. Electric energy meter is the direct billing interface between utility grid and consumers; and has undergone several advancements in the last decade. In Nigeria, electricity billing commenced from the initial use of post-paid meters. In post-paid system, there is no controlled use of electricity from the consumer's side. Power wastage on the consumer's side is high, due to lack of efficient planning of electrical consumption. Meter readers go from house to house to check consumer energy usage after which bills are prepared. Hence, the post- paid system is characterized by inconsistent billing arising from high billing error estimates. An inconsistent billing system leads to constant complaints by consumers, low consumer satisfaction, and hence poor public perception of service providers. The aftermaths of these are uncontrolled loss of revenue. 
The problems of unstable, inadequate and unreliable power supply in Nigeria has been linked to the power sector's inability to generate enough revenue to cover its operating costs let alone its huge capital expenditure requirements [1]. At the heart of this problem lies the method employed in service drop to residential buildings in Nigeria. A utility-approved single phase or a three phase service drop is normally wired to residential buildings according to the types and capacities of loads intended to be powered, with the applicable billing meter (single phase or three phase meter) wired in. But overtime, experience shows that this is no longer the norm, as today almost all residential buildings are serviced by three phase drop, with or without a single phase meter. A three phase meter is rarely installed by residential buildings. Now if a fuse of a powered substation transformer suddenly trips for any other reason such as phase overload, earth fault, line fault, etc. the residential consumers connected to that phase quickly and in a frenzied manner change or transfer their phases to the next available phase, from their own installed three-phase service fuse cut-out ports. Due to current surge on that very phase, the line fuse located in the feeder pillar soon trips to clear that feeder. Next all consumers transfer their loads to the next available phase. The feeder fuse then trips in a shorter time. This consumer attitude continues until all feeders' fuses go out and a total area blackout results. The results of the frequent and cyclical phase changing by residential consumers are: frequent distribution transformer and phase/feeder fuses breakdown, unreliability and unavailability of supply (brown-outs, black-outs), unnecessary revenue and manhour losses, frequent intervention calls by consumers, disputes over bill payments, service disconnection and reconnection problems by utilities, etc., which eventually portrays the utilities in bad light.

Cost recovery simply means recouping what was invested in providing services. Cost recovery is closely related to tariff. Tariffs imply payments made by electricity consumers. They are streams of revenue from the users that would enable investment cost to be recovered [2]. Tariff in the power sector may be defined as the aggregate price paid by the final consumer of electricity. Tariff collection enables the provider of electricity whether public or private investor to recover costs of energy consumed. Obviously the public sector finances invested in electricity supply are provided from tax payers' money and other sources of Government revenue. To ensure continued supply of the service and long-term sustainability, there is the need to recover all costs associated with the power service.

Presently, there has been an increasing desire to install digital pre-paid meters to bill consumers according to their consumption. It automates the meter reading, carries out prepaid recharging function and enables the exchange of consumed data information between the grid and consumer. Details of customer consumption information sent by the prepaid energy meter may be stored in the grid computer for future verification [3]. Electricity supply disconnection is achieved when the preloaded credit is exhausted.

Electricity billing system, in residential applications could be realized with either of single phase or three phase energy pre-paid meters. Considering that over $60 \%$ of utilities customers fall within the residential R2 class which significantly affects the revenue collection of utilities companies, effective, accurate and reliable means of collecting it must be followed. The electricity energy meter and system of billing is very critical to cost recovery and sustainability of service in terms of quality, convenience and continuity of service. In this $21^{\text {st }}$ century, electric utility management, public utility regulators and energy consumers have realized the need to have an economical and effective way of achieving satisfactory reliability levels of electric service. To realize this objective, a system must be engineered to provide the type of reliability needed at the lowest possible cost [4-5]. It is easy to invest in distribution capacity, but recouping that which was invested is of paramount importance as every business was started in the first place for profit, which in turn is re-invested for further capacity expansion. Hence the mode and manner of billing electric energy consumers is at the heart of failure or success of power distribution companies.

Various research works have gone into improving the power system in terms of management, billing, tariff plans and so on. Some of these include, the application of a new Multi-Year Tariff Order to improve revenue generation [1], the design and introduction of Power Billing System (PBS) with online capabilities for better administrative purposes [6], and the development of microcontroller based automatic trip control system for energy management using GSM wireless technology [7]. Research activities have also gone into the development of automated energy metering systems capable of remotely monitoring and controlling the distribution company's database [8]. The effect of voltage unbalance on the operation and performance of three phase distribution transformer has also been investigated [9]. Questionnaire-based surveys have been carried out to evaluate electricity supply, state of billing meters [10], as well as establishment of factors that contribute to the convenience offered by the prepaid billing system as opposed to the post-paid system [11]. In this work, reference was made to relevant rates and billing categories in [12-13].

This research therefore seeks to establish that a billing system that is phase-constrained will make for a reliable and available electricity supply that would eliminate the trouble of panic phase-changing by electricity consumers. 


\section{Concept of and Need for Phase-Constrained Billing}

(A) What is Phase-Constrained Billing: This an electricity billing system that utilizes penalty factor(s) to account for the use of more phases than that designated for the customer assigned electricity meter. This arises due to the fact that a customer wants some degree of freedom to move to another power supply phase in the event that the assigned phase has no available supply or has poor power quality. It gives the customer some degree of redundancy above other users with same grade of metering device.

It is desired to model a phase constrained billing system that generates electricity bills for consumers based on the number of phases they bring into their residences. We foresee that such a system could improve the availability, reliability and possibly the lifespan of the neighbourhood distribution substation transformer by systematic manipulation of customer behaviour through the service line connections and billing. Fused links depict the power flow path to the billing meter.

Fig. 1 illustrates the phase-constrained billing scheme. The topmost is the normal supply for single phase meter having just two lines. There is no option for a customer to change phase thereby exhibiting zero degree of freedom. The next has two phases connected to a single metering device showing one degree of freedom, and three phases connected to a single phase meter follows indicating two degrees of freedom for the customer. Finally, the lowest shows three phase supply to three phase meter which is normal for industrial or three phase equipment. It is constrained in the sense that no customer will have more than one phase (two supply lines) incoming for single phase meter, except with formal application and approval from the supplying utility. When approved, the customer pays for it by the introduction of a penalty factor in the tariff computation. Also, it is accommodated in the nearby distributions transforms' phase load allocation. The penalty factor increases as the degree of freedom granted the customer and the cost of providing redundancy in the distribution transformer load allocation.

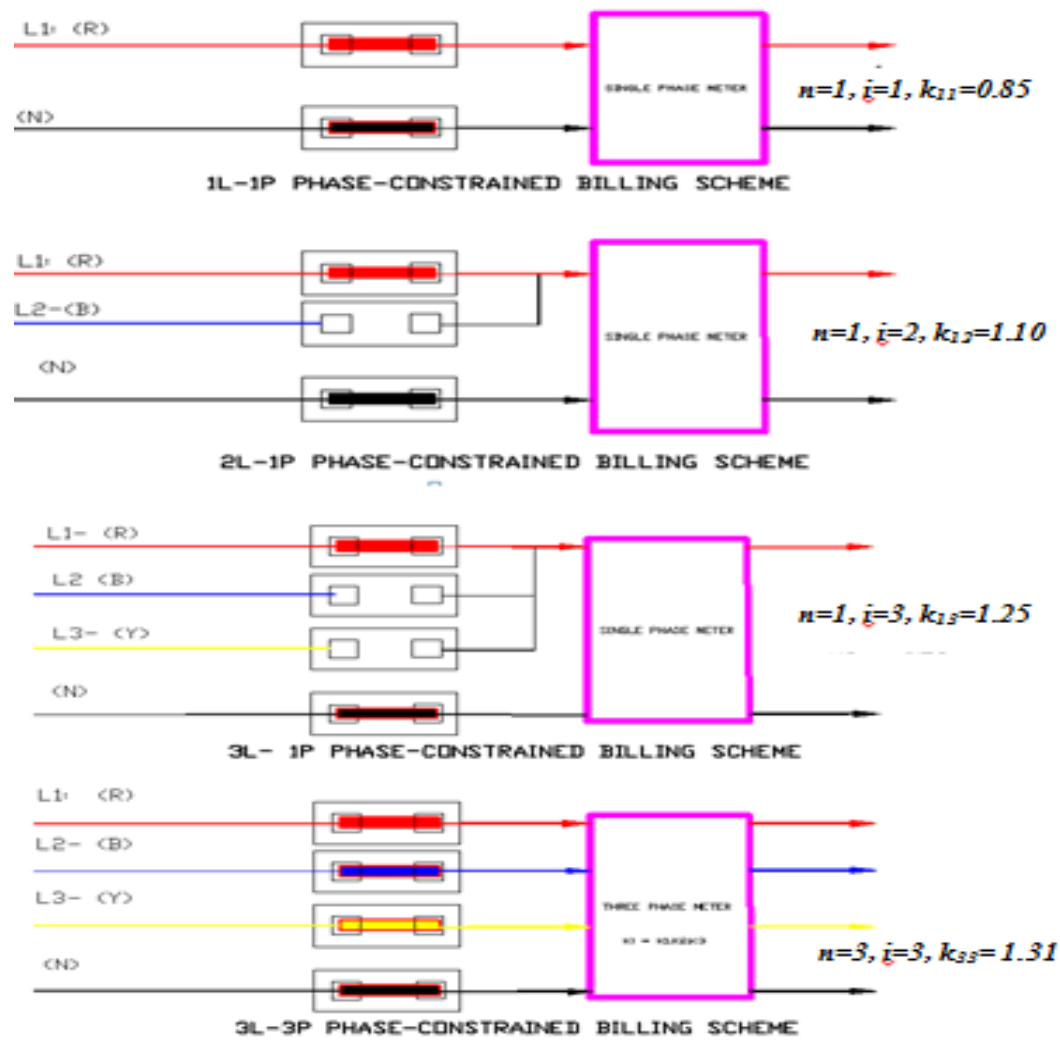

Figure 1: Phase-constrained billing scheme

\section{(B) Need for Phase-Constrained Billing System}

Unfortunately in Nigeria and most other developing countries, due to frequent outages and irregular supply of electricity arising from multifarious reasons including phase faults, customers usually pay higher fees to ensure that they have all three phases incoming (i.e. 4 wire supply) to their homes despite the fact that their electricity meters and appliances are single phase. A common scenario is that when there is supply in all three phases, the tendency is high that most homes connect to phase "A" leaving " $\mathrm{B}$ " and "C" phases. When phase the voltage in phase "A" drops, the whole neighbourhood will move to the next phase "B" leaving phase " $\mathrm{C}$ ". If supply in phase " $\mathrm{B}$ " is lost, everyone reverts to the remaining phase " $\mathrm{C}$ ". 
Worst cases arise at the instant when the normal supply is seen; most households usually connect to phase "A" since that is the $1^{\text {st }}$ phase before trying other phases. Due to the fact that no one is really sure of how low the power will stay, they rush to switch on inductive loads like water pumping machines and refrigerators. The attendant surge leads to overloading of the distribution transformers, particularly in this era of deregulation where the privately owned distribution companies load the system very close to limit to maximize profit. Considering the fact that distribution (service) transformers are designed to have maximum efficiency at lower loads, the overloading leads to customers residing close to transformer site having high voltages/low currents while those customers residing farther will experience low voltages/high currents [14 - 15].

From the foregoing, it may be stated that the consequence of unregulated, unplanned, unrecorded and very frequent change of phases by electricity end-users is transformer overload which are short and unplanned. Power transformer is one of the most important and expensive components in electric grid [16 -17], and therefore its performance affect the whole system. Whenever a power transformer is overloaded beyond its nameplate rating, there are risk and consequences as aptly captured in [14 - 19]:

(i) Accelerated aging: This is one of the main consequences of overloading a power transformer; and it leads to increase in operating temperature which influences transformer aging failure.

(ii) Burning winding insulation leading to complete transformer failure: The higher the loading the higher the generated heat which leads to burning of the winding insulation.

(iii) Severe loss of insulation life due to bubble and gas formation in the oil if the overloading last more than 30 minutes (the allowed short time overload according to IEC standard) [19].

(iv) Reduction of dielectric strength of the transformer insulating material due to gas bubbling from the insulating conductors and adjacent metallic structural materials.

(v) Reduction of transformer short circuit strength due to temporary deterioration of its mechanical properties at high temperature.

(vi) Increase in voltage regulation through the transformer due to increase apparent power loading and possibly dropping of power factor.

(vii) Expansion of oil due to increased top oil temperature rising above the standard limit.

(viii) Leaking of gaskets, loss of oil and extreme dielectric failure resulting from increased pressure in bushing.

Overall, due to these frequent changes of phases and attendant service transformer overloading with its dire consequences as outline above, there is more power outages because transformer life span in Nigeria is far below its expected normal life span of thirty years [14] in developed countries. In order to avoid the huge loss of materials, man-hours, revenue and in very extreme cases life, there is need to introduce constrained phase billing in Nigerian electricity tariff structure since it may cost more to pull out the extra incoming phases in single phase metered residential buildings. This will enable utilities to plan and accommodate all possible phase changes and appropriately balance the loads.

\section{Modelling of Phase-Constrained Billing}

From first principle, the exponential forms of energy consumed, $\boldsymbol{E}_{\boldsymbol{c}}$ and the basic energy consumption cost, $\boldsymbol{E}_{c c}$ for a composite load is respectively written as:

$E_{c}=n I V T e^{j \theta}$

$E_{c c}=n I V T R_{t} e^{j \theta}$

By combining some of the cost parameters defined in Table I as stipulated by electricity market regulators and decomposing the complex exponential operator using Euler's theorem, the electricity cost model (BILL) for the phase-constrained billing scheme (3) is obtained:

$B I L L=\left(1+R_{v}\right)\left(n k_{n i} I V T R_{t} \cos \theta+F_{c}\right)-C_{m r}+(1+\alpha) A_{\mathrm{rr}}$

Applicable parameters, symbols, dimensions and limits employed in the billing scheme are defined in Table I. The mean values are computed using (4) and (5):

$\bar{X}=\frac{\sum f_{i} \cdot X_{i}}{N}$

$\overline{X_{g}}=\frac{\sum \overline{X_{l}}}{N}$

Where: $\boldsymbol{i}$ : rank of scale from 1 to $5 ; \boldsymbol{X}_{i}$ : weight of respondent's answer choice; $\overline{\boldsymbol{X}}$ : weighted mean for a Likert item; $\overline{\boldsymbol{X}_{\boldsymbol{g}}}$ : Mean Average for a given group of hypothesis; $\boldsymbol{f}_{\boldsymbol{i}}$ : response count or frequency; $\boldsymbol{N}$ : frequency/count. 
Improving Distribution System Performance in Deregulated Electricity Industry Using Phase-..

Table I: Nomenclature for phase-constrained electricity billing scheme

\begin{tabular}{|c|c|c|c|c|}
\hline $\mathbf{S} / \mathbf{N}$ & Parameter & Symbol & Dimension & Remarks \\
\hline 1 & Number of Phases & $n$ & Nil & $n=1$ or 3 \\
\hline 2 & Number of Electric Service Lines & $i$ & Nil & ${ }^{\top}$ Reg. \\
\hline 3 & Energy Consumption & $E_{c}$ & KW.h & $\geq 0$ \\
\hline 4 & Energy Consumption Charge & $E_{c c}$ & Naira (N) & $\geq 0$ \\
\hline 5 & Power factor (pf) & $\cos \theta$ & Nil & $0.70 \leq p f \leq 1.00$ \\
\hline 6 & Value Added Tax (VAT)* & $\boldsymbol{R}_{v}$ & $\%$ & 5 \\
\hline 7 & Tariff Rate* & $\boldsymbol{R}_{t}$ & N/KW.h & MYTO II, 2012 \\
\hline 8 & 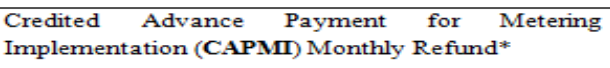 & $C_{m r}$ & Naira (N) & $\geq 0$ \\
\hline 9 & Monthly Asset Recovery Fixed Charge* & $F_{c}$ & Naira (N) & MYTO II, 2012 \\
\hline 10 & Previous Month Arrears & $A_{r r}$ & Naira (N) & $\geq 0$ \\
\hline 11 & Current Month Arrears & $A_{\text {cr }}$ & Naira (N) & $\geq 0$ \\
\hline 12 & Arrears Allowable Margin & $\boldsymbol{A A M}$ & Naira (N) & $\geq 0$ \\
\hline 13 &  & $\boldsymbol{k}_{n i}$ & Nil & $\begin{array}{l}\mathbf{k} 11=0.95, \mathbf{k}_{12}=1.10 \\
\mathbf{k}_{13}=1.25, \mathbf{k}_{33}=1.31\end{array}$ \\
\hline 14 & Monthly Incremental Penalty Factor on Arrear ${ }^{\top}$ & $\boldsymbol{\alpha}$ & $\%$ & $1.0 \leq a \leq 3.0$ \\
\hline 15 & Arrear Cut-Off Factor ${ }^{\top}$ & $\boldsymbol{\beta}$ & Nil & $0.5 \leq \boldsymbol{\beta} \leq 2.5$ \\
\hline
\end{tabular}

\section{Implementation}

Since it is thought that having more than one phase of electric supply to residential buildings significantly contributes to overloading of distribution transformer, resulting from frequent phase-changing; it is then necessary to sample customers' attitude, awareness and satisfaction in a bid to seek for ways of introducing customer-side load management using the concept of phase-constrained billing system.

Analysis of respondents' data was completed as follows:

(i) A total of 300 structured questionnaires (Appendix 1) was prepared and distributed to respondents (or customers) within the location of transformer substations.

(ii) Frequency Distribution Table was prepared from the returned respondent(s) data, and analysed using descriptive statistics.

(iii) Questionnaires were analysed based on the weighted mean in (4), as a measure of central tendency to assess the degree of influence of each factor (Appendix 2).

The Mean Base Table, based on the 5-point Likert scale [20] was adopted as the method of respondent data analysis [21], with scales defined as follows:

Strongly Agree (SA): 5; Agree (A): 4; Neutral (N): 3; Disagree (D): 2; and Strongly Disagree (SD): 1.

\section{Results and Discussion}

The field survey carried out had respondents of at least thirty years, self - employed, civil servants or employees of private companies. Three hundred questionnaires were distributed; with two hundred and eighteen returned comprising of one hundred and twenty eight males and ninety females respectively responding, yielding a total response rate of $72.7 \%$.

The following results were obtained by statistical evaluation of the mean based on Appendix 2 Table.

i. Group A: Frequent phase changing attitude by respondents creates feeder unbalance.

The group average mean integer value of 3 (actual $=3.26$ ), signifies that respondents were largely indifferent to this concept. Hence they remained neutral (N) in A1, A2, A3, A7 and A8. Respondents disagree (D) in A4, rejecting increased bill for bringing in or retaining multiple electric service lines. They also disagree (D) in A6 that "phase changing is the right action to perform". However, respondents agree (A) in A5 implying that if the 1-electric service line they bring into their residence is stable and 'cheaper', it would be preferred to having or retaining multiple lines.

ii. Group B: Phase constrained electricity supply will reduce phase unbalance problems and increase availability and reliability.

Group average mean integer value of 4 (actual $=4.20)$ implies that consumers agree that phase constrained supply could mitigate substation problems brought about by consumers' actions. Hence they agree (A) in B9, B10, B11 and B12. 
iii. Group C: Utilities' attitude (slow response and inconsistent billing) encourages sharp practices.

A group average mean integer value of 3 (actual $=3.33$ ) implies neutrality $(\mathrm{N})$ of consumers to this hypothesis. Respondents agree in $\mathrm{C} 13$ that lack of prompt response by utilities workers encourage sharp practices, but disagree (D) in $\mathrm{C} 14$ and $\mathrm{C} 16$ signifying that electricity bill is still a grey area. Respondents remain neutral $(\mathrm{N})$ in $\mathrm{C} 15$ despite that a greater percentage $(37.6 \%)$ disagrees, as they have to pay their bills all the same.

iv. Group D: Unenforced or absence of applicable legislation(s) contributes to phase imbalance.

Being a policy matter, a group average mean integer value of 3 (actual=3.71) shows that respondents are largely neutral $(\mathrm{N})$ or indifferent to this hypothesis. The Likert scale weighted mean of D17 is neutral $(\mathrm{N})$ despite that $38 \%$ of respondents strongly agree (SA). Respondents disagree (D) in D18 implying that it is better to call utility workers for intervention.

However, respondents agree (A) in D19 and D20 that tampering with electricity installations must be seriously addressed.

\section{Conclusion}

The paper presented phase-constrained electricity billing system in the computation of electricity tariff in deregulated electricity markets as a means of improving distribution system performance. The authors were of the view that the electricity distribution system in Nigeria and other developing countries where there exist more than one phase incoming for a single phase electricity meter gave room to frequent, unguided and unplanned jumping from one phase to another by electricity consumers leads to service transformer overload.

It went further to x-ray the dire consequences of prolonged overloading of distribution transformers which overall lead to their shorter life spans with attendant frequent power outages. Considering the important role of power transformers in the electricity grid and its cost, the authors deemed it fit that imposing a penalty on customers who use more that required phase for improved degree of freedom or redundancy will go a look way to reduce the number of customers who engage in such act. Furthermore, any possible change of phase would have been provided for in the load planning. The proposed model was validated using results realized from statistical evaluation of customer behavior and utilization index based questionnaire responses obtained from a field survey. Analysis is the questionnaire that the willingness of electricity consumers of various shades accepting the models if incorporated in the Nigerian Electricity tariff. Application of model could help Regulatory bodies and related authorities implement a fair utilization based electricity metering and billing system.

\section{References}

[1]. NERC (2012) Multi-year Tariff Order for the determination of the cost of electricity sold by distribution companies for the period 1 June 2012 to 31 May 2017 (MYTO) II (2012 - 2017), Abuja, Nigerian Electricity Regulatory Commission. pp. $54,55$.

[2]. Ofoegbu, G. N., Emengini, S. E , “ Recovery of Cost of Electricity Supply in the Nigerian Power Sector", Research Journal of Finance and Accounting. 4(17), 2013, pp 130-131,

[3]. Deepakraj, S., Murmu, C. P. “A Remote Electricity Billing System”, . National Institute of Technology, Roukela, 2012.

[4]. Billington, R., \& Alan R., Reliability evaluation of power systems (2 ${ }^{\text {nd }}$ ed.). London: Plenum Press, 1996.

[5]. Brown, R. E., Electric power distribution reliability (2 ${ }^{\text {nd }}$ ed.). U.S.A: C.R.C. Press, 2009.

[6]. Adegboyega, A., Gabriel, A. A. and Ademola, A. J., Victor, A. I., " Design and Implementation of an Enhanced Power Billing System for Electricity Consumers in Nigeria", IEEE African Journal of Computing and ICT. 6(1), 2013, pp. 49-58.

[7]. Sukhumar, S., Aravind, P. M. and Manivannan, L. “ GSM Automatic Trip Control System for Energy Management”, International Journal of Innovative Research in Science, Engineering and Technology, 2013, .pp 2 (12).

[8]. Abhinandan, J., Dilip, K., Jyoti, K., "Smart and Intelligent GSM Based Automatic Meter Reading System", International Journal of Engineering Research and Technology (IJERT),, 2012, pp1(3).

[9]. Edan, M. K., "Effect of Unbalanced Voltage on the Operation and Performance of a Three Phase Distribution Transformer", Journal of Babylon University, Engineering Sciences. No. 5, vol. 21, 2013, pp. 2-5.

[10]. Abdulwahab, L., “ An Assessment of Billing Electricity Consumers via Analogue Meters in Kano, Nigeria by Kano Electricity Distribution Plc", Bayero Journal of Pure and Applied Science, University of Maiduguri, Nigeria., 2009, 2 (1); pp. $27-33$.

[11]. Alam, M. J., Shahriar, F. M., “ Electricity Billing Systems at Residential Level in Sylhet City: Is pre-paid system perceived as a better option by the subscribers?”, Industrial Engineering Letters 2 (3), 2012.

[12]. Usman, A. A., Factsheet on Electricity Fixed Charge, 2013.

[13]. Eko Electricity Distribution Plc- EKEDC, Commencement of the Credited Advance Payment for Metering ImplementationCAPMI., 2013.

[14]. Shayan Tariq Jan, Raheel Afzal and Akif Zia Khan, "Transformer Failures, Causes and Impacts", International Conf. on Data Mining, Civil and Mechanical, Bali, Indonesia, Feb 1-2, 2015.

[15]. Radu Godina, Eduardo M. G. Rodrigues, Joao C. O. Matias and Joäo P. S. Cataläo, "Effect of Loads and Other Key Factors on OilTransformer Aging: Sustainability, Benefit and Challenges", Energies 2015, 8, ISSN 1996-1073, pp12148, 27 October, 2015.

[16]. Nawzad Rashid, "Short-time Overloading of Power Transformers", Master Thesis, Royal Institute of Technology Stockholm Sweden, 2011, pp $3-5$

[17]. IEEE Standard (C57.91-1995) Guide for Loading Mineral Oil-Immersed Transformers

[18]. Nordman, H. , Rafsback, N. and Susa, D. "Temperature Responses to Step Changes in the Load Current of Power Transformers", Power Del. IEEE Trans.Vo. 18, Issue 4, 2003, pp 1110 -1117.

[19]. PSERC Publication 11-02, "Transformer Overloading and Assessment of Loss-of-Life for Liquid Filled Transformers", final project [20]. report, Feb. 2011, pp. 2037. 
Improving Distribution System Performance in Deregulated Electricity Industry Using Phase-..

[21]. Rob, J., Likert items and scales. Methods fact sheet, University of Strathclyde, 2011

[22]. Sallam, A. A., \& Malik, O. P., Electric distribution systems. New Jersey. John Wiley \& Sons, Inc., March 2010.

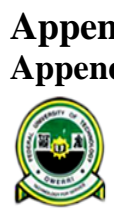

Appendix

Appendix 1: Survey Questionnaires

Federal University of Technology P.M.B. 1526, Oweni. Department of Engineering and Engineering Technology Postgraduate School

Research Questionnaire $\mathrm{No}$

It is thought that having more than one phase of electric supply to residential buildings significantly $A$. contributes to overloading of distribution transformers. When residential consumers bring in 2- or 2 . 3-phases instead of 1-phase into their residences, they engage in panic changing of phase from one to another whenever their connected phase fails. This creates unbalance in the transformer, trips all $A$. fuses and results to a total blackout of the whole neighbourhood. In view of deregulation and 3 . handover of distribution to private companies, this survey seeks for ways to introduce customer-side load management to enhance efficiency of supply, improved power quality, ensure improved and $A$. regularly available power at reduced cost to end users.

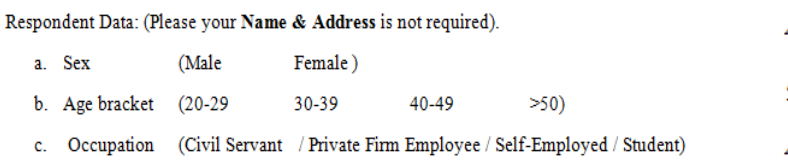

Underline the appliance(s) you use in your house: Air Conditioner, Submersible pump, Voltage Stabilizer, Refrigerator, deep freezer, electric fan, Inverter/Charger, CRT TV, LCD TV/LED TV, microwave oven, 6. blender, washing machine, electric stove or cooker, electric iron, electric kettle, electric jug water heater, Audio system, incandescent (old type)bulbs, energy saver bulbs, satellite decoder. 7. During power failure, it is better to wait for power to return than changing phase. $\begin{array}{llll}\text { Strongly AgreeB. Agree } & \text { C. Neutral } & \text { D. Disagree } & \text { E. Strongly Disagree }\end{array}$ During power failure, I change over because I have more than 1-phase in my residence. $\begin{array}{lllll}\text { Strongly Agree } & \text { B. Agree } & \text { C. Neutral } & \text { D. Disagree } & \text { E. Strongly Disagree }\end{array}$ Ground faults and directly joining the phases (short circuits) in residential buildings can damage fuses, feeder pillars, transformers and hence make the power supply unreliable and unavailable. $\begin{array}{lllll}\text { Strongly Agree } & \text { B. Agree } & \text { C. Neutral } & \text { D. Disagree } & \text { E. Strongly Disagree }\end{array}$ B. Balancing of residential buildings across the distribution phases can reduce or prevent the trippin Balancing of residential buildings across the distribution phases can reduce or prevent the tripping
(or damage) of transformer fuses, hence making the power supply reliable and available. $\begin{array}{lllll}\text { Strongly Agree } & \text { B. Agree } & \text { C. Neutral } & \text { D. Disagree E. Strongly Disagree }\end{array}$ $\begin{array}{lllll}\text { Strongly Agree } & \text { B. Agree } & \text { C. Neutral } & \text { D. Disagree } & \text { E. Strongly Disagree } \\ \text { Changing from one phase to another during power failure disrupts this balance and leads to overload. }\end{array}$ $\begin{array}{lllll}\text { Strongly Agree } & \text { B. Agree } & \text { C. Neutral } & \text { D. Disagree } & \text { E. Strongly Disagree }\end{array}$ Electricity consumers are partly responsible for blown fuses when they all change phase $A$
indiscriminately, hence reducing reliability of power supply.

$\begin{array}{lllll}\text { Strongly Agree } & \text { B. Agree } & \text { C. Neutral } & \text { D. Disagree } & \text { E. Strongly Disagree }\end{array}$ Electric utility workers contribute to power supply unreliability and availability when they fail refise to respond promptly to intervention calls to repair problems quickly.

Strongly Agree $\quad$ B. Agree $\quad$ C. Neutral $\quad$ D. Disagree $\quad$ E. Strongly Disagree $\quad A$.

My monthly electric bill fairly reflects my electricity consumption

$\begin{array}{lllll}\text { Strongly Agree } & \text { B. Agree } & \text { C. Neutral } & \text { D. Disagree } & \text { E. Strongly Disagree }\end{array}$

I find it difficult to pay my bills because the bills sent to me do not reflect my true consumption.
Please TICK your best choice to show how much you agree or disagree with the statement.

Bringing only one (1) phase to my residence makes power supply unreliable.

Strongly Agree $\quad$ B. Agree $\quad$ C. Neutral $\quad$ D. Disagree $\quad$ E. Strongly Disagree

Bringing 2- or 3-phases guarantees reliable supply to my residence

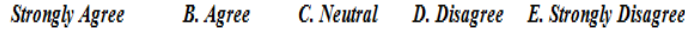

Bringing 2- or 3-phases does not guarantee reliable supply to my residence.

Strongly Agree $\quad$ B. Agree $\quad$ C. Neutral $\quad$ D. Disagree $\quad$ E. Strongly Disagree

Would you like to bring in or retain your 2- or 3-phase supply with an increased monthly bill

$\begin{array}{ccccc}\text { Strongly Agree } & \text { B. Agree } & \text { C. Neutral } \quad \text { D. Disagree E. Strongly Disagree }\end{array}$

Would you maintain 1-phase supply, if it is reliable and cheaper than bringing in 2- or 3-phases.

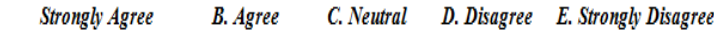

Changing from one phase to another during power failure or outage is the right action to perform.

Strongly Agree $\quad$ B. Agree $\quad$ C. Neutral $\quad$ D. Disagree $\quad$ E. Strongly Disagree

My electricity bills are paid because of services delivered satisfactorily.

$\begin{array}{rrrrr}\text { Strongly Agree } & \text { B. Agree } & \text { C. Neutral } & \text { D. Disagree } & \text { E. Strongly Disagree }\end{array}$

Electric supply from area transformers will be reliable and better if govermment makes a law that all residential buildings in the area served by the transformer must bring in only 1-phase from distribution lines.

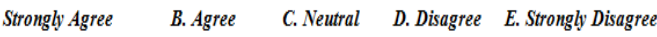

In event of faults on the line or substation, it is far better and easier to call the local electricians around for quick intervention than calling the electric utility workers.

$\begin{array}{lllll}\text { Strongly Agree } & \text { B. Agree } & \text { C. Neutral } & \text { D. Disagree } & \text { E. Strongly Disagree }\end{array}$

Electricity consumers can contribute in making power supply reliable and available when they stop tampering with public power supply installations and notify the authorities in event of fault

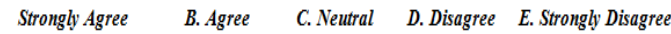

20. As an electricity consumer, it is illegal and constitutes a serious offence to tamper with your electric utility installations and billing meter in your residence.

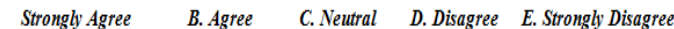

Appendix 2: Questionnaire Analyses (Mean Base Table)

Group A: Research Hypothesis 1 - 8

\begin{tabular}{|c|c|c|c|c|c|c|c|c|c|c|c|c|c|c|c|}
\hline \multicolumn{15}{|c|}{ Mean Base Computation for Research Survey Based on the 5-Point Likert Scale (LS) } & \multirow{3}{*}{ 鹿 } \\
\hline$\overline{\bar{g}}$ & Research Hvpothes is (or Likert Items) & \multirow[b]{2}{*}{ SA } & \multicolumn{4}{|c|}{ Response Frequency } & \multirow{2}{*}{$\begin{array}{c}\begin{array}{c}\text { Chec } \\
\mathbf{k} \\
\text { Sum }\end{array} \\
\\
\sum \mathbf{f}=\mathbf{n}\end{array}$} & \multirow{2}{*}{$\begin{array}{c}\mathrm{x} 1 \\
\mathrm{SA}^{* 5}\end{array}$} & \multirow{2}{*}{$\begin{array}{l}X 2 \\
A^{* 4}\end{array}$} & \multirow{2}{*}{$\begin{array}{c}\mathrm{x} 3 \\
\mathrm{~N} * 3\end{array}$} & \multirow{2}{*}{$\begin{array}{c}\mathrm{X} 4 \\
\mathrm{D} * 2\end{array}$} & \multirow{2}{*}{$\begin{array}{c}\mathrm{X5} \\
\mathrm{D} * 1\end{array}$} & \multirow{2}{*}{$\begin{array}{c}\Sigma(\text { LS }) \\
\Sigma x\end{array}$} & \multirow{2}{*}{$\begin{array}{l}\text { Mean } \\
\Sigma \mathrm{X} / \mathrm{n}\end{array}$} & \\
\hline A & $\begin{array}{l}\text { Frequent Phase-Changing attitude by consumers creates feeder } \\
\text { unbalance }\end{array}$ & & A & $\mathbf{N}$ & D & SD & & & & & & & & & \\
\hline 1 & $\begin{array}{l}\text { Bringing only one (1) phase to my residence makes power supply } \\
\text { unreliable. }\end{array}$ & 68 & 63 & 9 & 44 & 34 & 218 & 340 & 252 & 27 & 88 & 34 & 741 & 3.40 & $\mathbf{N}$ \\
\hline 2 & Bringing 2-or 3-phases guarantees reliable supply to my residence. & 46 & 76 & 5 & 54 & 37 & 218 & 230 & 304 & 15 & 108 & 37 & 694 & 3.18 & $\mathbf{N}$ \\
\hline 3 & $\begin{array}{l}\text { Bringing 2- or 3-phases does not guarantee reliable supply to my } \\
\text { residence }\end{array}$ & 46 & 68 & 10 & 56 & 38 & 218 & 230 & 272 & 30 & 112 & 38 & 682 & 3.13 & $\mathbf{N}$ \\
\hline 4 & $\begin{array}{l}\text { Would you like to bring in or retain your 2- or 3-phase supply with an } \\
\text { increased monthly bill. }\end{array}$ & 33 & 49 & 17 & 64 & 55 & 218 & 165 & 196 & 51 & 128 & 55 & 595 & 2.73 & D \\
\hline 5 & $\begin{array}{l}\text { Would you maintain 1-phase supply, if it is reliable and cheaper than } \\
\text { bringing in 2- or 3-phases. }\end{array}$ & 114 & 85 & 2 & 13 & 4 & 218 & 570 & 340 & 6 & 26 & 4 & 946 & 4.34 & A \\
\hline 6 & $\begin{array}{l}\text { Changing from one phase to another during power failure or outage is the } \\
\text { right action to perform. }\end{array}$ & 14 & 50 & 22 & 70 & 62 & 218 & 70 & 200 & 66 & 140 & 62 & 538 & 2.47 & D \\
\hline 7 & During power failure, it is better to wait for power to return than changing 1 & 65 & 50 & 9 & 75 & 19 & 218 & 325 & 200 & 27 & 150 & 19 & 721 & 3.31 & $\mathbf{N}$ \\
\hline \multirow[t]{2}{*}{8} & $\begin{array}{l}\text { During power failure, I change over because I have more than 1-phase } \\
\text { in my residence. }\end{array}$ & 45 & 105 & 14 & 24 & 30 & 218 & 225 & 420 & 42 & 48 & 30 & 765 & 3.51 & $\mathbf{N}$ \\
\hline & & \multicolumn{12}{|c|}{ AVERAGE MEAN FOR GROUP A } & 3.26 & $\mathbf{N}$ \\
\hline
\end{tabular}


Improving Distribution System Performance in Deregulated Electricity Industry Using Phase-..

\section{Group B: Research Hypothesis 9 - 12}

\begin{tabular}{|c|c|c|c|c|c|c|c|c|c|c|c|c|c|c|c|}
\hline B & $\begin{array}{l}\text { Phase-Constrained electricity supply will reduce phase unbalance } \\
\text { problems and increase availability and reliability. }\end{array}$ & SA & A & $\mathbf{N}$ & D & SD & $\sum \mathrm{f}=\mathbf{n}$ & $\mathrm{SA}^{* 5}$ & $A^{*} 4$ & $\mathrm{~N} * 3$ & $D * 2$ & $D^{*} l$ & $\sum x$ & $\begin{array}{c}\sum \mathrm{X} / \mathrm{n} \\
(2 \mathrm{dec} \mathrm{pl})\end{array}$ & \\
\hline 9 & $\begin{array}{l}\text { Ground faults and directly joining the phases (short circuits) in residential } \\
\text { buildings can damage fuses, feeder pillars, transformers and hence make the } \\
\text { power supply unreliable and unavailable. }\end{array}$ & 86 & 99 & 14 & 12 & 7 & 218 & 430 & 396 & 42 & 24 & 7 & 899 & 4.12 & A \\
\hline 10 & $\begin{array}{l}\text { Balancing of residential buildings across the distribution phases can reduce or } \\
\text { prevent the tripping (or damage) of transformer fuses, hence making the } \\
\text { power supply reliable and available. }\end{array}$ & 105 & 87 & 9 & 8 & 9 & 218 & 525 & 348 & 27 & 16 & 9 & 925 & 4.24 & $A$ \\
\hline \multirow[t]{2}{*}{12} & $\begin{array}{l}\text { Electricity consumers are partly responsible for blown fuses when they all } \\
\text { change phase indiscriminately, hence reducing reliability of power supply. }\end{array}$ & 109 & 75 & 12 & 12 & 10 & 218 & 545 & 300 & 36 & 24 & 10 & 915 & 4.20 & A \\
\hline & & \multicolumn{12}{|c|}{ AVERAGE MEAN FOR GROUP B } & 4.20 & A \\
\hline
\end{tabular}

\section{Group C: Research Hypothesis 13 - 16}

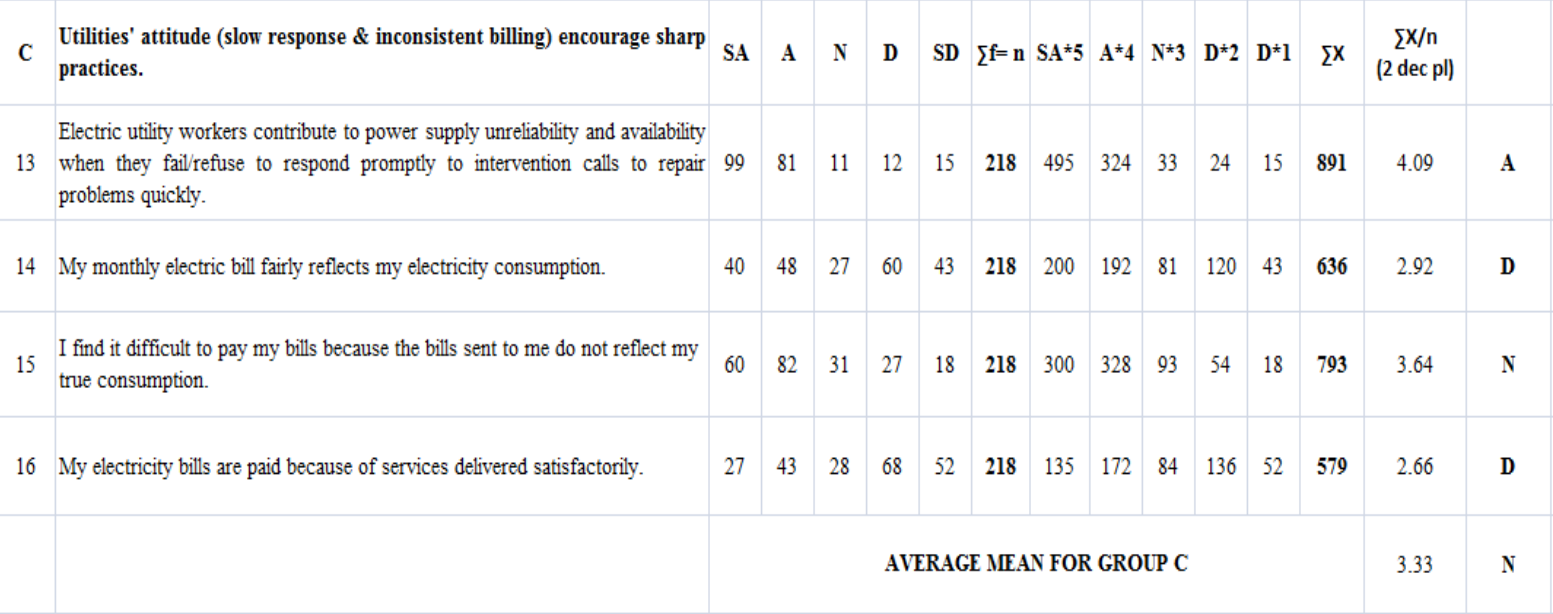

\section{Group D: Research Hypothesis 17 - 20}

Unenforced or absence of applicable legislations contributes to phase unbalance.

Electric supply from area transformers will be reliable and better if

\begin{tabular}{ll|l|l|l|l|l|l|l|l|l|l|l|l|l|l|l|}
17 & government makes a law that all residential buildings in the area served by the & 83 & 71 & 13 & 25 & 26 & $\mathbf{2 1 8}$ & 415 & 284 & 39 & 50 & 26 & $\mathbf{8 1 4}$ & 3.73 & $\mathbf{N}$
\end{tabular} transformer must bring in only 1-phase from distribution lines.

In event of faults on the line or substation, it is far better and easier to call the

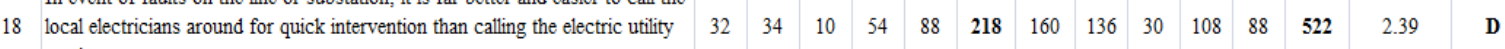
workers.

Electricity consumers can contribute in making power supply reliable and

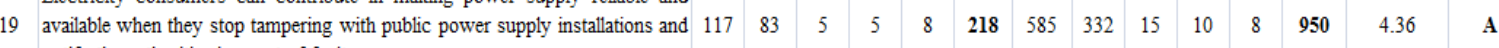
notify the authorities in event of fault.

As an electricity consumer, it is illegal and constitutes a serious offence to

\begin{tabular}{|l|l|l|l|l|l|l|l|l|l|l|l|l|l|l|}
20 & tamper with your electric utility installations and billing meter in your 130 & 67 & 6 & 3 & 12 & $\mathbf{2 1 8}$ & 650 & 268 & 18 & 6 & 12 & $\mathbf{9 5 4}$ & 4.38 & $\mathbf{A}$
\end{tabular} residence. 